\title{
HISTORIE Y GESCHICHTE EN LOS CUADERNOS NEGROS DE HEIDEGGER*
}

\author{
VINCENZO VITIELLO \\ Università S. Raffaele, Milán
}

\begin{abstract}
RESUMEN: Más allá de las necesarias observaciones al uso sobre el antisemitismo de los Cuadernos negros de Heidegger, escritos entre 1931 y 1948, el ensayo propone una importante paradoja: estos cuadernos, exposición - ahora pública- de un incesante trabajo artesanal sobre el destino del (¿propio?) mundo, giran en torno a dos nociones, de difícil traducción: Geschichte y Historie. La Geschichte correspondería al modo en que, desde el desarrollo - interpretado- del ser, éste da cuenta de sí mismo, de sus envíos y de su agotamiento, en espera de un nuevo inicio. Por el contrario, la Historie correspondería a la representación "científico-técnica» con que la Modernidad da cuenta de sí y de su pasado, en cuanto degradación secularizada del cristianismo. La paradoja consistiría, entonces, en que, por un lado, sería la Geschichte (en cuanto «historia-del-ser») la que entendería a la Historie como la última peripecia de una errancia (dado que, en los años 30 del pasado siglo, ambos movimientos habrían coincidido en Europa), que llevaría a su autodestrucción. Pero, por su parte, la Historie misma da cuenta de la Seinsgeschichte como un modo más, entre otros (y no el más afortunado ni científico) de explicar la historia. Así, Occidente, falto de raíces (de pagus: el «país»), se encaminaría a su ocaso. Heidegger: pagano convencido, cristiano a su pesar.
\end{abstract}

PALABRAS CLAVE: Heidegger; Cuadernos negros; pólis griega; Hegel; San Pablo; cristianismo - paganismo - judaísmo.

\section{Historie and Geschchte in Heidegger's Black Notebooks}

ABSTRACT: Beyond the usual necessary remarks on antisemitism in Heidegger's Black Notebooks, this paper offers a substantial paradox: Black Notebooks (1931-48), the exposition of an unceasing craftwork on the fate of the world (his own?), revolve around two difficult notions to translate, Geschichte and Historie. They are both usually understood, the former as a chronological account of contents that «really» happened in time (history strictly speaking), the latter as the more or less self-interested writing of these (historiography).Heidegger dismisses this interpretation (that would involve "something" separate from its narrative), and offers instead to understand both notions as selfrepresentation. Geschichte would correspond to the way in which, departing from the -interpreteddevelopment of being, this accounts for itself, for its delivery and exhaustion, awaiting a new start. On the contrary, Historie would correspond to the «techno-scientific» representation with which Modernity accounts for itself and its past, as the secularized degradation of Christianity. The paradox then is that, on the one hand, it is Geschichte (as «history-of-being") that would understand Historie as the latest turn of events in some wandering (considering that both movements would have been coincident in Europe in the 1930s), which would lead to its self-destruction. Yet on the other hand, Historie itself accounts for Seinsgeschichte as just another way, among others, (not the most fortunate or scientific) to explain history. Thus, the rootless (devoid of "pagus»: the country) West would head towards decline. Heidegger: a committed pagan, a Christian in spite of himself.

KEY WORDS: Heidegger; Black Notebooks; greek polis; Hegel; Saint Paul; christianity - paganism judaísm.

Texto traducido del original inédito en italiano por Leonardo Mattana. 


\section{WEGE - NICHT WERKE}

Éste es el título que Heidegger eligió para su propia «Edición integral» (Gesamtausgabe $\left.{ }^{1}\right)$ : Senderos, caminos, no obras. Y los Cuadernos negros, particularmente, son eso: senderos, caminos que, según el orden de publicación dictado por el autor, debían aparecer al final. No desde luego por temor al juicio de sus contemporáneos sobre las afirmaciones relativas al nazismo y el antijudaísmo contenidas en esos Cuadernos. Del hecho de que Heidegger no tuviera este tipo de preocupaciones dan testimonio sus no pocas declaraciones públicas al respecto, y de particular manera la de Bremen, en 1949, dentro de un ciclo de conferencias en el que puso al mismo nivel la mecanización de la industria alimentaria en agricultura y la «fabricación de cadáveres en las cámaras de gas y en los campos de exterminio» ${ }^{2}$ La razón de destinar los Cuadernos de tapa negra al final de la Gesamtausgabe era más intrínseca. Esos Cuadernos representan la autobiografía filosófica del autor y, al mismo tiempo, la historia del mundo en los trágicos años que van de 1932 a 1948. Aparecen una vez la obra acabada, al igual que lo está al final de cada historia el juicio que se expresa sobre la misma. Ciertamente, la comparación de Ser y Tiempo con la Fenomenología del Espíritu de Hegel y El Capital de Marx —al poner de relieve la sucesión progresiva de 60 años entre esas obras: 1807, 1867, 1927, casi un número mágico en la historia del ser-, y de su propia fecha de nacimiento con las de nacimiento y muerte de Hölderlin, Wagner y Nietzsche..., denota claramente la alta consideración que el filósofo tenía de sí mismo, pero también el carácter de su filosofía, naturaliter «histórica» ${ }^{3}$. Heidegger se "veía» en la historia. Sólo que, entonces, debemos preguntarnos qué es lo que él entendía por «historia». Y aquí empiezan las dificultades.

Heidegger distingue netamente Geschichte de Historie, viendo aquélla como el acontecer, como Geschehen del ser, y ésta como la auto-representación del acontecer sobre la base de las categorías de la ciencia y la técnica modernas ${ }^{4}$. Esta división no debe ser reconducida a la tradicional distinción entre res gestae e historia rerum gestarum: Historie y Geschichte son, ambas, acontecimiento y representación del acontecer, res gestae e historia rerum gestarum. Y ello, no en el sentido «formal» de que también la representación de la historia es resultado del obrar: un acontecimiento, al igual que el acontecer es, en cuanto consciente de sí, pensamiento, es decir autorrepresentación ${ }^{5}$, sino en el sentido «material» de que la Historie, la representación «científica» de la historia, es la efectiva

\footnotetext{
1 Ed. Klostermann, Frankfurt/M. Los volúmenes de esta edición serán citados, en el texto y en nota, con la sigla GA seguida por el número de volumen, de página y, cuando sea necesario, del párrafo.

2 Heidegger, M., Bremer und Freiburger Vorträge. Gesamtausgabe (= GA) 79.

3 Cf. respectivamente $G A 97$, p. 131, y 94, p. 523.

4 Sobre la identidad de esencia (Wesensgleichkeit) de Técnica y Historie: cf. GA 95, p. 383.

5 Cf. Gentile, G., Sistema di logica come teoria del conoscere, vol. 2, Sansoni, Firenze 1940-423 , pp. 279-306.
} 
realidad (Wirklichkeit) del acontecer del mundo moderno. Para la ciencia y la técnica modernas no hay más mundo "realmente efectivo» (wirklich) que la «imagen» que ellas construyen del mundo. Ellas son las potencias creadoras de este mundo. Desde la perspectiva de la Historie es entonces la Geschichte, o mejor la Seinsgeschichte, una mera «interpretación», una representación solamente "pensada», y sin embargo inefectiva, unwirklich, del acontecer. Por otro lado, es la misma Seinsgeschichte la que atribuye «realidad», efectividad a la Historie, cuando ve en la imposición de ésta su posible destrucción (Zerstörung) 6 . Sin embargo, así como la esencia de la técnica y de la ciencia modernas no es ni técnica ni ciencia ${ }^{7}$, tampoco la esencia de la Historie es historisch, sino geschichtlich. De ello se sigue que la potencia manifiesta en la Historie no le pertenece a ésta, sino a la Geschichte. Esto, desde la perspectiva de la Seinsgeschichte.

¿Superficie y fondo, como en Hegel? ¿Viene entendida la Seinsgeschichte como la estructura profunda de la historia, conocida no por el Historiker, sino por quien indaga la historia de manera pensante (denkender Geschichtsforscher), por ser éste capaz de captar lo que viene a darse en lo profundo, y por tanto de pre-ver lo nuevo que avanza? ${ }^{8}$ No, aquí no es Hegel el aludido, sino, si acaso, Nietzsche, porque la superficie: la Historie, no realiza, no lleva a «cumplimentación» lo profundo: la Seinsgeschichte, sino que, por el contrario, la niega. La relación de Heidegger con Hegel es, en muchos aspectos, parecida a la que tiene con Aristóteles. Si el vínculo con ambos es fuerte, ello se debe a que la oposición es fortísima, determinada no en vano por el reconocimiento de su "primacía», de su Vorrang en la historia del pensamiento. Son los muros más altos, los que hay que atravesar o derrumbar para abrir nuevos caminos. Y aquello a lo que Heidegger se atreve es muy arriesgado, si es que en el mismo acontecer está la amenaza de la esencia de la historia. Pero Heidegger ama repetir con Hölderlin "Wo aber Gefahr ist, wächst / das Rettende auch»'. Son versos, como es sabido, que hablan de la inaprensible proximidad del Dios.

\section{HISTORIE}

- Se ha dicho- no es sólo interpretación, sino que es también potencia activa: una potencia que no tiende más que a sí misma, como bien muestra la economía industrial, en la que la producción de bienes no se hace en vista de la satisfacción de las necesidades o del consumo, sino de la producción

6 Un tema, éste, que retorna a continuación en los Cuadernos; cf., en particular: GA 95, pp. 206-212, y 97, p. 91: «Der Historiker ist die personifinizierte Negation der Geschichte».

7 Cf. Heidegger, M., Die Frage nach der Technik, in Id., Vorträge und Aufsätze (=VA), 3 Bde, Neske, Pfullingen $1967^{3}$, I, pp. 5-36.

8 Hegel, G. W. F., Die Positivität der christlichen Religion, en Id., Werke in zwanzig Bänden $(=W)$, Suhrkamp, Freiburg/M., 1969 ss, 1, p. 203.

9 Hölderlin, F., «Patmos», vv. 2-3. 
misma, la cual se conserva en la medida en que se acrecienta continuamente a sí misma. El consumo ha pasado de ser el fin a ser el medio, pero un medio que "gobierna» el todo, porque si la producción no crece el sistema industrial entra en crisis. Por eso se crean necesidades «artificiales». Está claro que, aquí, "potencia» no denota una "facultad humana», sino una estructura ontológica, al igual que «sujeto» no significa ya «hombre», sino «función». Es, por tanto, la jüngeriana «movilización total» (totale Mobilmachung), la configuración del «eterno retorno del igual» más conforme a nuestro tiempo ${ }^{10}$. Pero Jünger es sólo una «referencia» para Heidegger. Fuente primaria y determinante de su concepción del sujeto moderno es la metafísica de la voluntad de poder, que designa la culminación de la metafísica - más allá de Hegel. En diversos lugares, Heidegger se detiene sobre el fragmento nietzscheano que dice: "Imprimir al devenir el carácter del ser, ésta es la suprema voluntad de poder» ${ }^{11}$. Replegado sobre sí mismo, el sujeto moderno deja de ser «sujeto» para volver a ser "sustancia». El final se enlaza con el inicio: la última palabra del pensamiento occidental repite, wiederholt, la primera palabra, la palabra de Anaximandro ${ }^{12}$.

El horizonte de la Historie — de la Historie, empero, observada desde la Seingeschichte - se ha dilatado enormemente: lo moderno tiene raíces antiguas. Antes aún que en la idea de Platón y la ousía de Aristóteles, es en el fragmento de Anaximandro donde Heidegger localiza la primera manifestación originaria de la identidad que niega la motilidad (Bewegtheit) del ser. El sujeto moderno es heredero y cumplimentación de aquella «identidad originaria»: la voluntad de querer, en cuanto «sustancia» y "fundamento» del movimiento, es la «necesidad» (tò chreôn) que en el movimiento niega el movimiento, que ontifica al ser, convirtiendo «ser» — sein- de verbo en sujeto, en subjectum, hypokeímenon, ousía. De sujeto a sustancia: es la crítica más dura que se pueda dirigir a Hegel: la inversión de su principio de verdad ${ }^{13}$. Lo moderno, el historicismo moderno, la cumplimentación de la historia de la metafísica, es el verdadero enemigo de la historicidad del ser. Está de tal modo en su contra, que es capaz de romper todo vínculo de contigüidad con el pasado. Ésta es la Zerstörung, la destrucción de la Geschichte, llevada a cabo por la técnica moderna en la tierra de la historia.

3. De hecho, la política moderna no tiene ninguna verdadera relación con la pólis griega, o sea con el «lugar» originario de la comunidad humana ( $G A$ 96 , p. 43, § 22). No es origen, sino producto. Y producto, como los hombres que en ella operan, de la técnica y de la ciencia. En realidad, ella misma es

10 Jünger, E., Die totale Mobilmachung, en Id., Sämtliche Werke (= SW), Klett-Cotta, Stuttgart, VII, 1980, pp. 119-142; cf. también Der Arbeiter, SW VIII, 1981, pp. 9-317.

11 Cf. Nietzsche, F., Kritische Studienausgabe (=KSA), dtv-de Gruyter, München-BerlinNew York 1988, Bd. 12, p. 312, n. 7 (54); Heidegger, M., Nietzsche $(=N), 2$ vols., Neske, Pfullingen 1961, II, pp. 283-291.

12 Heidegger, M.,Holzwege, Klostermann, Frankfurt/M 19725 , p. 307.

13 Cf. Hegel, G. W. F., Phänomenologie des Geistes, Meiner, Hamburg 1952', p. 19. 
una técnica, un actuar gobernado por el entendimiento calculador. Por tanto, no está ligada al «lugar», a la «tierra». La forma más evolucionada de la política moderna, la política planetaria — hoy se diría: global—, es literalmente «idiotismo». Malévolamente, Heidegger precisa que usa este término en el significado del étimo griego ídios, es decir, no para indicar la enfermedad de la psique, sino la originaria separación de los individuos, que es lo que estaría a la base del moderno concepto de ser-en-común (GA 96, pp. 260 e 265). La crítica heideggeriana a la política moderna, como técnica e idiotismo, afecta lo mismo a Hobbes que a Schmitt, despachado con un: «piensa [al estilo] liberal (denkt liberal).» La oposición schmitteana amigo/enemigo no está de hecho pensada a partir de la Sorge - la constitución ontológica originaria de la «esencia del hombre» (Dasein) - sino a partir de la relación entre individuos originariamente separados. La política —dice Heidegger «de modo concluyente»- es para Schmitt una esfera de la experiencia humana, un ámbito particular, como el arte, la lógica, la economía ${ }^{14}$. Es antropologismo.

Sobre el «cristianismo histórico» (Christentum) se leen, en los Cuadernos, juicios aún más severos. Aun reconociendo que aquél ha suscitado "capacidades del espíritu [...] sin las cuales no es posible pensar la historia occidental» - un juicio que, como veremos, se tornará en su contrario-, no deja de notar que «desde hace mucho tiempo ha perdido toda fuerza originaria», para concluir después: "Las formas del cristianismo moderno» son "las formas genuinas de la ausencia de Dios (Gott-losigkeit)». Y la razón, explica, está en que el cristianismo ha hecho (gemacht) "historisch su propia Geschichte» ${ }^{15}$. Y si a veces hace alguna concesión en el plano «moral» al cristianismo que remite a la tradición medieval, no deja de poner de relieve su inadecuación «histórica», especialmente cuando los tiempos exigen "grandes decisiones». En general, Heidegger es más áspero con el cristianismo protestante: de la teología dialéctica dice que no merece siquiera ser mencionada (GA 94, p. 51, § 132); después, cuando nombre a su principal representante: Karl Barth, lo define como «más fariseo» que los antiguos fariseos (GA 95, pp. 395-396). Ahora bien, aunque no pueda excluirse que sea debido también a la educación y los afectos familiares (GA 94, p. 320), su mayor respeto al catolicismo —o mejor, quizá: la menor aspereza que reserva a éste, ya que de todas formas no se priva de decir que tampoco el catolicismo guarda ya relación con la tradición medieval-, es bien difícil de explicarlo por la cercanía de cierta "política católica» al nazismo ${ }^{16}$. Con los «cristianos alemanes» (deutsche Christen), que, como

14 Cf. Heidegger, M., Seminare. Hegel-Schelling:Hegel «Rechtsphilosophie», Wintersemester 1934/35, GA 86, p. 174; Schwarze Hefte, GA 95, p. 232-233, § 58a, y 235, § 62.

15 GA 94, pp. 522-23. Para un más articulado estudio de la sujeción de la iglesia y de la religiosidad cristianas al dominio (Herrschaft) de la Historie y del Historismus: «es decir, de la edad moderna», cf. en particular GA 95, pp. 110-111.

16 En una reflexión de los años entre 1938 y 1939, Heidegger alude a una contigüidad, en realidad no muy clara, entre el nacionalsocialismo y el "catolicismo político» —ni cristiano ni eclesial, remarca, pero, universal, kathólon. Este "catolicismo» (das "Katholische»), que 
representantes de la Iglesia protestante, apoyaban con mayor convicción y en modo más notorio al nacionalsocialismo y a Hitler, fue de hecho bien duro ${ }^{17}$. La razón del distinto «trato» hay que buscarla más a fondo, en la filosofía de Heidegger, evidentemente mucho más cercana a la sensibilidad barroca del catolicismo, «romano y español», que al intelectualismo protestante, «nórdico y alemán».

Llegados a este punto, la pregunta que surge naturalmente es si la condena del Hebreo, en cuanto figura histórica del carácter abstracto de la ciencia y de la técnica moderna, y diversamente articulada y repetida en los Cuadernos negros, no involucre también, y por principio, al «nórdico» y al «alemán». La respuesta es clara: implicado está ciertamente el «alemán nórdico», ipero no el «bárbaro» nazista! ${ }^{18}$ Pero procedamos con orden. El antijudaísmo de Heidegger tiene varios aspectos - teológico, ético, político, histórico- que deben ser estudiados en su diversidad y en su complejo entramado.

Hay que empezar desde lejos, desde el concepto del Dios judío, el Dios «celoso» de la tradición. Heidegger se pregunta: ¿Qué Dios es ese dios que no soporta otros dioses a su lado? Un argumento que no es nuevo. Se encuentra ya en el joven Hegel. Y de estos «celos» — de estos tiránicos celos divinosdescienden todas las consecuencias de la falta de felicidad de la existencia hebraica, que debe anteponer su Dios a todo vínculo de afecto con la propia tierra y la propia casa, con el propio pasado y el propio futuro: los hijos - como los judíos en su larga historia, a partir de su padre Abraham, han aprendido duramente. Sin embargo, la denuncia de Heidegger versa sobre la ausencia de tierra, de tierra natal, de patria, que es típica del judío. El judío no tiene raíces. No tiene «ethos». ¿Qué implica esta falta de raíces?

En los Grundbegriffe der Metaphysik ${ }^{19}$ — un texto fundamental sobre el que deberemos volver-, Heidegger, para definir la «esencia del hombre», o Dasein, había tomado como criterio de valoración la relación con el mundo. Al ser de la piedra y del animal, definidos la una como weltlos («carente de mundo») y el otro como weltarm («pobre de mundo»), oponía allí Heidegger el ser weltbildend del hombre, el ser-capaz de dar forma al mundo. Welt tiene, en este contexto, una particular relación con el espacio. Mientras que la piedra es indiferente al "lugar» en el que se encuentra y el animal es totalmente tomado, conducido (benommen) por el ambiente (Umgebung) en el que vive (GA 29/30, p. 348), el hombre, en cambio da forma a su espacio, lo «habita»,

\footnotetext{
ha encontrado su forma auténtica en el Jesuitismo, «el arquetipo occidental de cualquier incondicionada obediencia, de la exclusión de cualquier autonomía del querer», no tiene nada que compartir — reafirma - con el medioevo cristiano. Su origen es romano y español, «para nada nórdico y absolutamente no alemán» (GA 95, p. 325-326).

17 «Cristianos alemanes: una interpretación errónea: no cristiana. sino anticristiana, de lo que es ser alemán»: GA 94, p.522.

18 «El nacionalsocialismo es un principio bárbaro (ein barbarisches Prinzip). Este es su rasgo esencial y su posible grandeza»: GA 94, p. 194, § 206.

19 Es la Vorlesung del semestre de invierno de 1929/30: GA 29/30.
} 
se cuida de él. En los Cuadernos, con explícita referencia a estas páginas de los Grundbegriffe, Heidegger corrige y complementa lo anterior: la piedra es ahora definida como feld- und weltlos: privada, no sólo de mundo sino también de «suelo»; el animal es ahora feldbenommen-weltlos: al igual que la piedra, carece de mundo, pero además se ve conducido, tomado por el suelo; solamente el hombre es weltbildend-erderschließend: sólo él forma mundo al hacer emerger tierra (GA 95, p. 282). Es la tierra, die Erde, no el simple suelo, lo que le es atribuido, en caso de que sea él quien la hace aflorar. Pero puede hacerlo porque él pertenece a ella, porque forma parte de ella. Es evidente que en los Cuadernos, la Inständigkeit, la «insistente persistencia»: el enraizamiento de Dasein en la tierra, ha tomado un mayor relieve ontológico. El «Da» no es ahora mundo, o no es ya sólo mundo: ahora es «tierra», también tierra. Es el "entre», das Zwischen, que une-divide tierra y mundo: el conflicto o Streit, el pólemos, como también viene llamado en Ursprung des Kunstwerkes, el texto que marca uno de los pasajes cruciales del itinerario de Heidegger ${ }^{20}$. Pero en el pólemos es la tierra, die Erde, la que rige (waltet), la que se hace-valer sobre el mundo, die Welt. ¿Cómo? No hay modo mejor de indicarlo que la ex-plicación «etimológica» que Heidegger hace de su propio nombre.

Heid-egger uno (einer) que se las ha con una tierra no cultivada, una landa (Heide), y la allana o traílla (eggt). Pero la traílla (Egge) debe ante todo ser precedida por un arado a lo largo del campo de piedras (GA 97, p. 62).

El nombre indica la tierra no cultivada (Heide) y la traílla (Egge) que allana la tierra, pero también, y en primer lugar, apunta a ese "uno» (einer), que se encuentra en el campo. No es un «uno cualquiera», sino un Terrae filius: ein Heide, un pagano. Heidegger es eso: un pagano. Acompaño este pasaje con otro, algo posterior.

«Europa»: tal es la forma moderna del olvido en el que Occidente (Abendland) ha quedado atrapado. El cristianismo (das Christentum), es decir la organización paulino-gnóstico-romano-helenística de la vida evangélica de Jesús, es la prefiguración (Vorform) de Europa. Ello nada tiene que ver con Occidente, porque repudia a Grecia (Griechentum) de la forma más insidiosa, a saber, invirtiendo la interpretación de ésta en favor de sus propios fines; pues Grecia vale en cuanto paganismo (Heidentum). (GA 97, p. 144).

Aquíno secitaaljudaísmo, sinoal cristianismo histórico(Christentum): citado, y duramente rechazado. Y junto a él es rechazada Europa, contraponiéndola a Occidente, la Tierra-del-Ocaso, en la cual, ahora, al Cristianismo no le viene reconocido ningún papel. Pero es evidente que el aludido en primer lugar es el Judío, desarraigado de la Tierra por su propio Dios: «la tierra es mía, y vosotros sois en lo mío forasteros y huéspedes». Así habla el Dios de nombre impronunciable al pueblo elegido, a sus hijos, (Levítico, 25, 23-24).

20 Cf. Holzwege, cit., pp. 7-68. 
4. Paganismo contra judaísmo. La crítica del intelectualismo, ya iniciada por Hegel y Husserl, alcanza con Heidegger una radicalidad que transforma el plano mismo del "conflicto»: ya no «lógico-cognoscitivo», sino "teológicopolítico». Es decir: no se trata de elaborar una forma de conocimiento - la «razón dialéctica» en Hegel, la «razón teleológica» en Husserl- más elevada que la del entendimiento calculador y mensurante; Historie y Geschichte no son, por expresarme con lenguaje hegeliano, "figuras de la conciencia», sino "figuras del mundo», en lucha entre ellas. De esta lucha depende el destino no sólo de Europa, sino también de Occidente. La Zerstörung de la Geschichte por obra de la Historie es una amenaza epocal. Lo esencial de la Historie es de hecho la Técnica, cuya operación consiste en sustraer la «sustancia» a las cosas, reduciéndolas a meros signos. La crítica de Heidegger va a la raíz del problema, a la mathesis universalis: la resolución del ser del mundo en «relaciones», esto es en números, cifras, fórmulas. La potencia de la ciencia y de la técnica modernas consiste en la disolución del cuerpo material del mundo: la tierra. Y cuando éstas no tengan ya más «materia» que consumir, únicamente les quedará el consumirse a sí mismas. (GA 97, p. 18). A la aniquilación del mundo seguirá la de los aniquiladores. En esta «condena», el pueblo judío no está solo...

Y es que, si no se entiende la radicalidad de la crítica heideggeriana a la ciencia moderna, que concierne in primis a la fundamentación cartesiana del saber, no se entenderán sus páginas sobre el Gestell: el «armazón» del ser propio de la ciencia y de la técnica modernas, el preludio del Ereignis ${ }^{21}$.

Estamos en el punto en que se torna la relación entre Historie y Geschichte; y los primeros encausados al respecto son los Judíos.

5. Primera pregunta: ¿cómo pueden considerarse conjuntamente la antigüedad «teológica» de la Erdlosigkeit, de la carencia de tierra propia del Judío, y la modernidad de su «esencia» (Wesen) técnica? ¿No se ha dicho, hablando de la política moderna, que, puesta al servicio de la técnica, no tiene nada que ver con la pólis griega? ¿No se ha dicho, hablando del cristianismo moderno, que éste ha roto todo vínculo con la Edad Media? ¿Cómo se explica esta "excepción» del Judío que es antiguo y moderno katà tò autó, en el mismo respecto? ¿Acaso sólo en el Judío tiene lo moderno un corazón antiguo?

En el Judío, en su esencia (im Wesen des Juden), se da evidentemente algo especial. Prueba de ello es Hegel, que, después de haber expresado un juicio durísimo sobre el pueblo judío, el más duro: "Abraham quiso no amar», lo distinguió de los demás pueblos, definiéndolo como «extraordinario» (ausgezeichnet) ${ }^{22}$; o Nietzsche, que, después de haber condenado a los judíos por ser un pueblo de chandalas o "parias», de débiles impotentes para enfrentarse

21 «Was wir im Ge-stell als der Konstellation von Sein und Mensch durch die moderne technische Welt erfahren ist ein Vorspiel dessen, was Er-eignis heißt.»: HeIDEgGER, M., Identität und Differenz, Neske, Pfullingen $1957^{3}$, p. 29.

22 Hegel, G. W. F., Der Geist des Christentums und sein Schicksal, W, 1, pp. 277 e 284. 
a la vida, escribe: «Los Judíos son el pueblo más notable de la historia mundial „23; así también Heidegger, el cual, con lo áspero de su juicio, eleva al Judío sobre los demás pueblos. De hecho, el Judío muestra en la Historie la oculta presencia de la Geschichte. Lo que en la Historie de los otros pueblos y de las otras religiones está dividido, lacerado, ignorado, está unido en la Historie del pueblo judío: la memoria del Dios que, en relación con el pueblo por Él mismo elegido, siente celos incluso de su Tierra - la «teológica» Erdlosigkeit-, y de la esencia de la técnica moderna. Esta unión, esta conexión de lo antiguo y lo moderno, es el rasgo característico de la Seinsgeschichte. Nietzsche, por citar un solo ejemplo, es en la lectura seinsgeschitlich de Heidegger un "platonizante antiplatónico», cuando teoriza la Umwertung aller Werte (N, I, pp. 231-242), la transvaloración de todos los valores; y en cambio es un preplatónico cuando sostiene el «eterno retorno de lo igual». Pero aún hay que añadir más: la Historie del pueblo judío no solamente liga el presente a la memoria del pasado, sino que muestra también el destino, la destinación «final» de Occidente. La Historie del pueblo judío revela el carácter escatológico de la historia. De la historia, y no solamente de la historia hebraica: la autoaniquilación de la Técnica y la autoaniquilación del Judío (GA 97, p. 20) —dos autonegaciones inseparablesson la autoaniquilación de la Historie.

No se trata de una justificación de la Shoah, sino de la condena del entero Occidente. ¡De Anaximandro a Nietzsche! Tal es el «preludio»: el Gestell.

Pero es también aquí donde se da la oposición de Heidegger al nihilismo. El sentido del «último Dios» es, a saber, que todos los dioses son últimos en el Zeit-Raum-Spiel, en el juego del espacio-tiempo del Ser, cancelado, tachado por una cruz. Es el sentido de la búsqueda del otro inicio, más antiguo que el primero $^{24}$. Y también el sentido "más verdadero» del paganismo de Heidegger, un paganismo sui generis, en el que se «advierte» —en el sentido viquiano del término- de la fraternidad existente entre Dionisos y Cristo, tomada por Heidegger de su Hölderlin ${ }^{25}$.

La oposición de Heidentum a Judentum adquiere, ahora, otras connotaciones. También en política. Empecemos por ésta.

\section{6. ¿DÓNDE ESTAMOS NOSOTROS?}

A finales de los años treinta del siglo pasado, la Historie se encuentra escatológicamente con la Geschichte. Hitler se ha consolidado en el poder. Con la asimilación de Austria, la Gran Alemania no es ya un objetivo, sino una realidad que ninguna potencia europea ha conseguido impedir. Los años de

23 Nietzsche, F., Der Antichrist. Fluch auf das Christenthum, KSA 6, p.191.

24 GA 95, p. 213. Sobre el tema, ver en particular, los Beiträge zur Philosophie (Vom Ereignis), GA 65.

25 Cf. Hölderlin, F., Der Einzige. 
Weimar son sólo el recuerdo de una pesadilla para la mayoría de los alemanes. Y la voluntad de expandirse, de conquistar el propio Lebensraum, un espacio vital del que nadie conoce los confines, deja de ser algo encubierto para ser declarada en voz bien alta. Polonia es el próximo objetivo. Densas nubes de guerra cubren una vez más el cielo de Europa, y desde Europa se expanden al mundo entero.

No a todos, ciertamente, pero sí a muchos de quienes habitan el mundo de la Historie les resulta entonces evidente que el tiempo apremia, que "ha sido acortado» (1 Cor. 7, 29). Heidegger se hace dramáticamente la pregunta: Wo stehen wir? ( ¿Dónde estamos?»), a sabiendas de que no es él el único en plantearla; pero sabe también que la mayor parte de quienes se hacen la pregunta lo hacen historisch y psychologisch, como si conocieran ya el lugar que habitan, y aún más a sí mismos. Y sin embargo «Wo stehen wir?» implica: «Wer sind wir?» ("¿Quiénes somos?»). Pero "¿existe una época que tenga conocimiento (kennt) de sí misma? ¿O acaso será reconocida (erkennt) sólo por la posteridad (Nachwelt)? Y, ¿qué significa aquí «reconocer»(erkennen)?». Nosotros - apunta dramáticamente el filósofo - no estamos a la altura de la pregunta: no sólo no sabemos el «dónde» ni «quién» está en ese «dónde», sino que no sabemos siquiera qué significa «hallarse». "Nosotros — concluye- no estamos (stehen) todavía, sino que nos limitamos a aferrarnos a la voluntad de vivir (Lebendigkeit) y a la racionalidad (Vernünftigkeit) propia del animal rationale» (GA 94, p. 443-445).

Heidegger no está inseguro, sino inquieto. Sabe que en el subsuelo de la historia se está preparando algo, y algo grande. Der Heide sabe que el primer paso que se da sobre el campo es él del arado que remueve la tierra para la siembra. Remover la Tierra es el fin de la Historie: el eclipse de Europa. Pero Europa es demasiado débil para acoger su propio eclipse. El eclipsarse exige fuerza. Pero... ¿quién tiene esta fuerza? (GA 94, pp. 480-481, § 100; y p. 484, § 105).

Esta pregunta «repite» la precedente: Wer sind wir? Pero, ¿`es legitima? ¿Está realmente, como se ha dicho poco antes, implicada en la primera: Wo stehen wir? En aquella pregunta, al «nosotros» no le viene reconocido ningún poder activo. «Estar» es algo que carece de toda facultas operandi. La piedra se limita a «estar».

Y sin embargo, ¿acaso no ha distinguido Heidegger la esencia del hombre (Da-sein) no sólo de la piedra, sino también del animal? ¿No es el hombre, por esencia —esto es, justamente por su arraigo en la Tierra-weltbildend, configurador de su mundo? Al hombre, que es quien hace su mundo, el mundo de la Historie, a la vez que está arraigado en la Tierra, en la physis ${ }^{26}$, debiera corresponderle un papel en la catástrofe de la Historie, la cual da señales del adviento del ser. De ahí que a la pregunta: Wer sind wir? se dé una primera respuesta: Die Brecher, «los infractores», los que rompen la dura corteza de

26 «Physis ist Sein im Sinne des Aufgangs»: GA 97, p. 264. 
la Historie para que el acaecer vuelva a acaecer, y el devenir a devenir (GA 95, p.58). ¿Pero quiénes son, quiénes pueden ser los Brecher, en esta Europa que no tiene siquiera la fuerza de eclipsarse (Untergehen)?

Los alemanes: "Principio" de los alemanes es la lucha por la propia esencia» (GA 95, p. 11). Heidegger — chu! ille miser — ve en el nazismo el cumplimiento de esta esencia. Si la raíz del error - el paganismo- tiene su grandeza, ínfimo es sin embargo su fruto. Yo no evocaré aquí, en defensa de Heidegger, la influencia de Nietzsche, el filósofo con el que en aquellos años en mayor grado se medía ${ }^{27}$. Intentar tal cosa sería algo que justamente se tornaría en su contra: Nietzsche había separado claramente a «los Griegos dionisíacos de los bárbaros dionisiacos», mientras que en la defensa por parte de Heidegger de la barbarie nazi no hay rastro distintivo alguno que pudiera recordar ni de lejos a la distinción nietzscheana entre las «fiestas de redención del mundo» que se celebraban en Grecia, y las Saceas babilonias ${ }^{28}$. Pero si, dejando aparte a Nietzsche, comparamos estas páginas de Heidegger sobre los «alemanes» con las de sus contemporáneos —Literaten, más que filósofos-, debemos reconocer que el filósofo sale de ese parangón realmente mal parado; y no en el aspecto literario, obviamente, sino en el de la duda y la interrogación, que sería lo propio ${ }^{29}$.

Volvamos al tema principal: el ocaso de Europa; a veces, extendido al ocaso de Occidente, al «final» de la Historie. ¿Qué debe entenderse por «final» de la Historie y el adviento de la Seinsgeschichte? ¿Estamos en el umbral de un nuevo mundo? ¿Es el anuncio de la segunda venida de Cristo? ¿De un Cristo pagano?

7. En los Beiträge zur Philosophie (Vom Ereignis), cuya redacción es coetánea a la de los primeros Cuadernos de tapa negra, Heidegger escribe Unter-gang (occasus) separando la palabra en sus componentes para evocar el étimo griego de katastrophé, de katà-strépho: trastornar, irse abajo, al fondo. El Unter-gehen, el «irse al fondo» de la Historie es la emergencia del Seinsgeschehen, del acontecer

27 Me refiero a los Cursos friburgueses de los años 1936-1941, que confluyeron en los dos volúmenes del Nietzsche, op. cit.

28 Nietzsche, F., Die Geburt der Tragödie, KSA 1, pp. 31-32; y Die dionysische Weltanschauung 1, KSA 1, p. 558. Es verdad que en los Cuadernos hay muchos «rastros» en sentido contrario: cf. las páginas sobre la «brutalitas» como perteneciente a la esencia del hombre en cuanto animal rationale: GA 95, pp. 394-397, § 42; GA 96, pp. 253-254.

29 Así, más articulada y «movida» es ya la relación Kultur/Zivilitation en Thomas Mann (y antes, en Gedanken im Kriege, donde el escritor defendía incluso la invasión germánica de la Bélgica neutral durante la primera Guerra Mundial, por no hablar del contemporáneo Friedrich und die grosse Koalition, y de las tumultuosas Betrachtungen eines Unpolitischen); "problemática» es también la relación entre Europa y el "ser alemán» en Musil (Das Hilflose Europa [1922], Der deutsche Menschen als Symptom [1923]). Me detengo aquí, pero la lista podría continuar con abundantes ejemplos, de Benn a Kraus o a Ernst Jünger (der Literat: GA 97, p. 70, y 171; pero ver también $G A$ 95, p. 370). 
del ser, o mejor: del evento del ser en cuanto acaecer ${ }^{30}$. Ocaso y resurgimiento. Ocaso y alborada, cómo dirá Ernst Jünger: «die Abenddämmerung des alten und die Morgendämmerung des neuen Zeitalters ${ }^{31}$. Con las debidas diferencias, parece oírse aquí el eco de Hegel, del Hegel que muestra cómo en el irse al fondo emerge el fundamento en las cosas mismas, como fundamento interno a ellas ${ }^{32}$.

La referencia a Hegel es inevitable: pero para señalar, una vez más, no la cercanía, sino la distancia. Porque el irse a fondo, el eclipsarse del fundamento, es en Hegel el propio ponerse en acto de éste: más que en las cosas mismas, un ponerse como siendo las cosas mismas. El fundamento hegeliano aparece en las cosas, porque es las cosas. La sentencia: «La cosa es, antes de existir» (die Sache ist, ehe sie existiert) dice lo mismo que aquello que, al final de la Fenomenología del espíritu, se muestra en la plena luz del saber, esto es: que el fin del entero itinerario de la conciencia, desde la sensibilidad hasta el saber absoluto, es «la revelación de lo profundo» (das Ziel ist die Offenbarung der Tiefe) ) $^{33}$. Lo profundo que, estando ya en el inicio, aunque de forma inconsciente, rige - oculto- el entero camino del pensamiento y, llegando a consciencia, confiere «sustancia» a las formas puras del conocer: "corpulencia» — diría Vico- a las abstractas «figuras de la conciencia», transformándolas en «figuras del mundo». El saber absoluto de Hegel es positivo, porque «pone» lo nuevo, transformando así el contenido «real», «efectivo» (wirklich) del mundo. Es positivo porque niega lo negativo: el pasado en el que el devenir se ha estancado. El saber absoluto de Hegel no se limita a llevar a cumplimentación el movimiento, sino que hace mucho más: instaura la motilidad misma del movimiento. Es, por tanto, antes de aparecer, de mostrarse.

El alba del nuevo mundo de Heidegger tiene en cambio los mismos «contenidos» del viejo mundo, exactamente los mismos. La revelación de la Seinsgeschichte "es» su velarse en la Historie. La tachadura en una cruz que Heidegger pone sobre «Seyn» indica que el ser se hace visible sólo cancelándose. Traducido en el lenguaje de Hegel, esto significa que en el ente hay ser, pero sin existir ni aparecer ${ }^{34}$. La diferencia entre ser y ente no está ni borrada (getilgt) ni asumida (aufgehoben), sino "olvidada»: das Seynt ist die Vergessenheit des Unterschieds (GA 97, p. 384). Y, en cuanto olvidada, viene liberada en su esencia $^{35}$. La diferencia entre ser y ente no es «objeto» de pensamiento, sino un modo de pensar el objeto, de hacer experiencia de éste; un modo que

30 Sobre el tema remito a mi art.: «Seyn als Wesung: Heidegger e il nichilismo», "AutAut», 1992/248-249, pp. 75-92.

31 JÜnger, E., An der Zeitmauer, SW, VIII, p. 515.

32 Hegel, G. W. F., Wissenschaft der Logik (=WL), II, W, 6, pp. 119-123.

$33 W L$, II, p. 122; PhäG, p. 564.

34 «Tampoco es el ente (Seiende) no es tampoco una aparición del ser (eine Erscheinung des Seyns).» GA 95, p. 244, § 77.

35 «El olvido del ser (Seinsvergessenheit) no es superado (aufgehoben) en el pensamiento rememorante (im Andenken), sino sólo liberado (be-freyt) en su esencia (Wesen)». Ib. p. 367. 
nunca puede ser exhaustivamente expresado en un enunciado, de modo que el decir que dice esta diferencia no puede sino desdecirse al decirla. De entre las muchísimas proposiciones disponibles en los Cuadernos negros -en las que la forma, fuertemente designada mediante oxímoros, da de suyo testimonio de la importancia que este pensamiento de la «diferencia olvidada» tiene en Heidegger - elijo estos dos ejemplos: «El pensamiento rememorante piensa el olvido»; "el no-olvido es un modo en el que el olvido se ha preparado su morada $»^{36}$. La brecha, pues, das Brechen que abre el "paso» a la Geschichte, no cambia el carácter errático de lo verdadero: «Ursprüngliche Wege sind IrrWege» ${ }^{37}$. Los caminos originarios son caminos de errancia. El «salto» de la Historie a la Geschichte no implica, por tanto, un cambio de "estado». Lo que cambia es el modo de estar. Por tanto, a la pregunta «Wo stehen wir?», no hay otra respuesta que: en la Historie. En la Historie stehen und bleiben, estamos y permanecemos. Y la pregunta, por ende, no es ya: «Wo stehen wir?»-sino: «Wie stehen dort, wo wir stehen?" ¿Cómo estamos allí donde estamos?

Es decisivo observar que, en el par ordenado Historie/Geschichte, esas dos preguntas introducen, de forma siempre más marcada, un tercer término: wir, nosotros. Esta inserción muta la relación Historie/Geschichte: ambas son - como sabemos desde el principio- potencias operativas, además de «formas» de conocimiento del obrar; mas ahora se nos dice que ellas no obran por si solas, sino que les hace falta (brauchen) un «tercero», el cual, en el conflicto entre las dos "potencias», ha aparecido como der Brecher: el «nosotros» que abre la brecha para que irrumpa el acontecer, el Geschechen de la Geschichte. Y a fin de evitar que este "tercero» sea interpretado con las categorías antropológicas y psicológicas propias de la metafísica tradicional, es decir de la Historie - lo cual impediría la proposición misma del problema, fundado justamente en la distinción entre Historie y Geschichte-, Heidegger, al plantear la pregunta: «Wo stehen wir?», ha aclarado desde el principio que es el «estar en el lugar» lo que permite identificar el «wir», y no al revés. Y es que: «el lugar (Ort) no es un sitio cualquiera a la mano (keine vorhandene Stelle», sino "la hendidura» (der Geklüft) del ser, con las posibilidades de las más simples decisiones (Entscheidungen).» Decisiones que conciernen justamente a «la posibilidad de la diferencia entre el ser y el ente»(GA 95, pp. 63-64). Pero, ¿no se había dicho que el «lugar» donde estamos (wo wir stehen) es la Historie? Es en la Historie, entonces, donde acontecen las decisiones más simples, esto es, las decisiones fundamentales. Por ejemplo, las concernientes a la Guerra Mundial, den Weltkrieg; al ocaso: el Unter-Gang de Europa, o a la kata-strophé de la propia Historie. El lugar («Ort») del que estamos hablando es el lugar del encuentro escatológico de la Historie con la Geschichte. ¿Dónde acontece este lugar? ¿Dónde está este lugar de la Historie?

36 "Das Andenken denkt die Vergessenheit»; "die Un-Vergessenheit selbst [ist] eine Weise, wie die Vergessenheit sich zu ihrer Einkehr bereitet hat»: GA 97, p. 281.

37 «Es el riesgo de errar lo que ordena el espacio intentado (versuchen) por ellas [por las vías originarias del errar].» GA 95, p. 214. 
La dirección final del itinerario hasta aquí recorrido — complicado, y hasta tortuoso- es clara: con la pregunta por el «lugar» y el «estar» del «nosotros», Heidegger, hablando de la historia del mundo, nos ha (re)conducido allí donde está en juego la esencia del hombre, nos ha hecho re-tornar al Da del Da-sein, el «ahí» del ser, donde son «posibles» las más simples decisiones del acontecer histórico. Resulta por tanto que el paso, o mejor: el salto de la Historie a la Geschichte —ese «salto» que exige una «ruptura» en la continuidad de la Historie - no conduce «fuera» de la Historie. La Geschichte no es otro lugar, al lado del lugar de la Historie; es otro modo de habitar el mismo lugar, la Historie. Consiste, por ende, en una transformación radical de la actitud, del modo de ser del Dasein. En el "salto», el estar-Ahí (Da-sein) no hace ni debe hacer otra cosa que lo que siempre ha hecho; pero lo hace, y lo debe hacer, de modo diverso. Lo que cambia es el modus operandi, no el "contenido» del obrar. Y es un cambio mucho más radical que el de cualquier otro cambio del obrar y en el contenido del obrar ${ }^{38}$.

Se acaba de decir poco antes que la pregunta «Wo stehen wir?» debe ser sustituida por la más comprensiva: "Wie stehen wir dort, wo wir stehen?» ( ¿Cómo estamos allí donde estamos?»). Se ha dicho también que, en la Historie, wir stehen und bleiben "estamos y permanecemos», vale decir: que la forma más radical de la mutación es el Stehenbleiben, el quedarse quietos, la detención, porque el lugar, el $\mathrm{Da}$ del Da-sein —el ámbito (la «hendidura», der Geklüf) de las «más simples» decisiones (o sea de las decisiones elementales, originarias y radicales) - es la Historie misma. ¿Qué cabe añadir para comprender que el "salto" de la Historie a la Geschichte es eso: un "salto", y no un simple paso - porque no concierne a la motilidad del movimiento, al acontecer del acontecimiento, al hacerse historia de la historia-, sino el origen del hacerse historia, la raíz del acontecer, la quietud que está antes del movimiento, a saber: la Tierra, la physis, el brotar o Aufgehen del acontecer? Lo que hay que añadir, ¿no es acaso que el acontecer, justamente al acontecer, olvida? Un olvido, éste, que no es el fruto de una «decisión», sino un hecho, el hecho que está «antes» de toda decisión: es la Faktizität misma del Dasein, el cual, al acontecer, acontece. Objeto de decisión es sólo el poder-volverse el Dasein a la Tierra, a la raíz, pero no para reunirse con ella - esto significaría negar el acontecer, replegándolo sobre sí, para llevarlo otra vez a la raíz- sino para recordar el abandono (Verlassenheit) y el olvido de la raíz misma. El olvido es la única forma en la que se da memoria del origen. La memoria del «ser (Seyn) [que], en agraz (Frühe), no es aún ser (Seyn).»(GA 97. p. 384). Lo cual equivale a decir que el ser es ser sólo al perderse en el mundo, en la Historie: donde propiamente (eigentlich) no-es.

38 También «las revoluciones — afirma Heidegger- difunden la apariencia de un nuevo inicio de la historia (Geschichte), y son sin embargo la máscara tras la que se expande una recomposición en el respecto histórico (im Historischen) -reproponiendo con algunos ajustes lo mismo que ha acontecido hasta ahora». GA 95, p. 53. 
«El errar es el más escondido don de la verdad ${ }^{39}$. Este don es estar-Ahí: «Das Da-sein ist Irre-sein ${ }^{40}$.

¿Es Heidegger el pagano errante?

8. El papel «central» del Dasein en la relación entre Historie e Geschichte viene vigorosamente confirmado en las segundas Anotaciones del volumen que cubre los años entre 1942 y 1948. «Sein und Zeit» —escribe Heideggerha sido mucho más que el título de un libro: perdura (bleibt) como «el único pensamiento de $m i$ vida», el que me ha sido "destinado». El pensamiento - precisa- de la "verdad del ser», buscada, interrogada en su esencia, por lo pronto (zuvor), como Da-Sein. Permanecer (Stehenbleiben) en este único pensamiento habría significado una «asidua meditación sobre la historia del ser, ilustrada a través de una profundización de la historia del pensamiento» (GA 97, pp. 174-177 y 181). Estas Anotaciones aclaran el sentido de la "torna» en el pensamiento de Heidegger mejor de cuanto lo hacen otros textos suyos, en particular aquellos en los que la Kehre parece cumplirse en la transición de la primacía del interrogar (Fragen) a la de la escucha (Hören), ya que es ésta la que proporciona su «objeto» al interrogar («aquello que deba venir a pregunta»: was in Frage kommen soll ${ }^{41}$. Pero ya en la Introducción a Sein und Zeit, en el parágrafo dedicado a la estructura formal de la pregunta, se decía mucho más que eso, a saber: se decía que en el interrogar está implicado, en cada «objeto» de la pregunta (das Gefragte) y en todo aquél que interroga (der Fragende), aquello que rige y orienta el entero proceso del interrogar, esto es: das Erfragte, la posibilidad del interrogar mismo: el Da-sein. Ahora bien, Da-sein no «es» esta posibilidad en el sentido de que ella le pertenezca, sino al revés: lo es en el sentido de que Da-sein —en cuanto tal, «interrogante»- pertenece a esa posibilidad. Lo posible - aquello posible que está más alto que lo real ${ }^{42}$ atraviesa de lado a lado al Da-sein, el cual, sólo en cuanto constituido en su ser por el ser-posible (Möglich-sein), tiene el poder-de-ser (Sein-Können) aquello que él, de vez en vez, «decide» ser. En esta estructura ontológica, en la que domina lo posible, hay una brecha, un vacío constituido por la escisión, interna a lo posible, entre "posibilidad» y "poder». En los Cuadernos, esta «brecha», este «vacío», tiene varias figuras y nombres diversos, según el nivel en el que se

39 Ib., "Ciertamente - sigue Heidegger- el errar (die Irre) no es aquí el «error» (der «Irrtum»), la falta bien definida (der festgestellte Fehler), el hecho de que falle (das Fehlen) la verdad como exactitud, sino el errar propio del Ahí, de estar-ahí (aquello que pertenece al ahí del ser-ahí: jenes, was zum $D a$-des Da-seins gehört).»GA 95, p. 14, § 13. Los fallos e inexactitudes son lo propio de las ciencias: ib., p. 16, §19.

40 «El estar-ahí es estar en error. Por ende, somos nosotros mismos los que estamos perdidos; y, en cuanto perdidos, al final nos encallecemos a nosotros mismos, aferrándonos a lo que nos es más cercano, como si fuera la cosa mejor.»: $G A$ 94, p. 228, § 68 .

41 Cf. Heidegger, M., Unterwegs zur Sprache, Neske, Pfullingen 19755, p. 175. Sobre la relación de la Kehre con el olvido del ser en su doble modalidad, inauténtica y auténtica, cf. GA 97, p. 370 .

42 Heidegger, M., Sein und Zeit (=SuZ), Niemeyer, Tübingen $1977^{14}$, p. 38. 
halle el análisis de la relación Historie/Geschichte: del Brecher o «infractor» a Geklüft o «hendidura». En Sein und Zeit, esta brecha, este vacío, tiene solamente un nombre: Faktizität, con el que Heidegger pretende subrayar el modo de ser de obrar del poder, la irreductibilidad a razón, fundamento o principio de ese obrar (wirken). Y es que, si el poder-ser (Sein-können) no viene dado sino en el ámbito del ser-posible (Möglich-sein), o lo que es lo mismo: si la decisión no viene dada sino en el ámbito de lo decidible, entonces lo posible, justamente por ser infinitamente más amplio que el poder, no determina a éste. La decisión, la Ent-scheidung en la que el poder-ser se determina, separando algo posible de los demás al "ponerlo en obra», es un hecho: el hecho que «cubre» el vacío entre lo posible y el poder, confiriendo de esta forma al acto de poder, a su Wirklichkeit, la apariencia del kath'hautó, de aquello que es "de suyo», fundado sobre sí. Esta infundada «factualidad» del poder es el mundo en el que «nosotros vivimos, nos movemos y somos» (Hechos, 17, 28); es la Historie, "das Tun Aller und Jeder» ${ }^{43}$, el hacer de todos y de cada uno, sin conciencia del "vacío», de la nada del propio ser. Faktizität dice en Ser y Tiempo lo mismo que Verfallenheit: caída, deyección. Dice «lo mismo» (das Selbe) que en la Seinsgeschichte será denominado como Seinsvergessenheit: olvido del ser, o como Seinsverborgenheit, ocultación del ser; según se ha dicho, olvido del origen, olvido de la physis. Olvido necesario como también se ha dicho-, porque no hay otro modo de poner en obra el acontecer que la separación del origen. La diferencia, entonces: la diferencia entre ser y ente, estriba absolutamente en la diferente modalidad de hacer experiencia del mundo, del acontecer del mundo. De un mundo que es uno y solamente uno: el mundo en el cual vivimos, nos movemos y somos (zômen kaì kinoúmetha kaì esmén), pero del que podemos tener experiencia propia (eigentlich) en la memoria: no del origen olvidado, sino del olvido del origen; $\mathrm{o}$, al contrario, tener experiencia impropia (uneigentlich) en el olvido incluso del olvido, que es lo que acontece en la cotidianidad (Alltäglichkeit) de nuestro común vivir en común (Mit-dasein).

La cita repetida de las palabras de Pablo implica una doble referencia: a la distinción «modal» entre Eigentlichkeit y Uneigentlichkeit de Sein und Zeit y a las páginas de los Schwarze Hefte sobre la diferencia, ella también «modal», entre Historie y Geschichte, si se enfoca desde la perspectiva del Da-sein, como se ha hecho en el precedente §7. Doble referencia que, mientras liga la oposición entre Historie y Geschichte a la de Eigentlichkeit y Uneigenlichkeit en la Eksistenz del Da-sein (ya que ambas son experiencias de la esencia de la verdad como error y errancia), pone en evidencia, al mismo tiempo, el origen de esta doble oposición «modal» en la distinción entre sozómenoi e apollúmenoi, entre salvados y réprobos, que es el tema central del curso friburgués del semestre de invernio de 1920/21, dedicado a Pablo. Los réprobos —explicaba entonces el joven Heidegger - no son los ateos, quienes no tienen fe, sino los creyentes, los pistéuontes, que equiparan el inquieto esperar de la fe, que vive siempre en

43 Hegel, G. W. F., PhäG, p. 300. 
taîs thlípsein, en las tribulaciones, con las certezas propias de los saberes del mundo. "No hay seguridad ninguna para la vida cristiana», decía, añadiendo luego: «es también la inseguridad constante lo que caracteriza los significados fundamentales de la vida fáctica (des faktischen Lebens)» ${ }^{44}$. Llegados a este punto, parece natural hacer mención de la distinción, expuesta en los Cuadernos, entre Christentum y Christlichkeit, entre cristianismo histórico-metafísico y cristiandad como fe en Jesús (y ello, en el doble sentido de «creer a Cristo y de creer en Cristo»: Glauben an Christus und in Christus (GA 97, p. 204).

Surge, inmediata la pregunta: ¿qué se ha hecho, dada esta reconstrucción, del «pagano» Heidegger? ¿Cómo surge su proclamado "paganismo», y con tal potencia que hasta le sugirió aquella sorprendente «etimología» de su nombre?

9. No hace falta buscar lejos. Ya en el curso de invierno de 1929-1930, Heidegger, retornando a la relación Möglich-sein/Sein-können, atribuye al Möglich-sein la capacidad (Kraft) de «determinar» la decisión del Sein-Können. La posibilidad deja de ser solamente el ámbito de las posibles elecciones del poder. De ser "posibilidad de com-posibles», pasa ahora a ser "posibilidad posibilitante», ermöglichende Möglichkeit (GA 29/30, § 76). Un paso, éste, decisivo. El vano, el vacío entre posibilidad y poder ha sido colmado, cancelado. Ahora no hay más que un único actor en la escena de la historia del ser: el ser mismo. Que se revela como y cuando «quiere». No: eso de «quiere» está ya de más. Digamos mejor: que se revela como y cuando se revela. El mismo velarse no es sino una forma de revelación, es decir una forma de ser. No un «modo» de hacer experiencia del ser, ya que no hay "quien» haga experiencia de ello: el "quién» ha sido completamente absorbido en el ser. El ser se da a sí mismo como se da. Siempre del mismo «modo», sean cuales sean los «contenidos» de su darse.

La misma distinción Historie-Geschichte — la distinción, digo ahora, no la oposición- deja de tener sentido, porque ya no es posible distinguir entre la esencia de la cosa y la cosa. Como en Hegel, «ist» y «existiert» se equiparan. Pero no sucesivamente — se piense esa equiparación como se piense: temporal o puramente lógica一; no: «es» y «existe» vienen equiparados desde el principio, dentro de la suprema tautología de: «das Ereignis ereignet», allí donde ser y ente dicen y son lo mismo. Lo mismo y lo igual, das Selbe y das Gleiche, sin distinción alguna.

Das Ereignis ereignet. ¿Es éste, acaso, su significado?

No, no lo es. Nunca lo ha sido. En la página de los Cuadernos antes mencionada, en la cual, con páthos no insólito, pero no por ello menos significativo, Heidegger explica que el único pensamiento sobre el que se ha interrogado toda la vida, no le había dado la «quietud» de la posesión, sino la inquietud de la falta. Para quien escribe, es imposible no enlazar estas palabras con las de Ser y Tiempo sobre la llamada de la conciencia (Ruf des Gewissens), la cual viene de mí, pero por encima de mí (SuZ, §57).

44 Heidegger, M., Phänomenologie des religiösen Lebens, GA 60, 1995, p. 105. 
Heidegger: pagano y cristiano a la vez, ciertamente no del cristianismo histórico (o «metafísico»), sino "paulino» - de su Pablo, el cual —superfluo es añadirlo- está por lo demás completamente ausente de los Cuadernos. Si Heidegger fue ferozmente antijudío, ello se debió (ésta no es sino una conjetura del intérprete) a que advertía en sí mismo una instancia «judaica» que él quería extirpar de sí: el sentido de extrañeza respecto a la Tierra, a la Pólis, a la Geschichte: todo ello, presente en el sentimiento mismo de pertenencia a la Tierra, a la Pólis, a la Geschichte.

En 1935 - un año después de su dimisión del Rectorado-Heidegger imparte un curso que lleva por título Einführung in die Metaphysik: «Introducción en la metafísica», no a la (zu der) metafísica. Parte fundamental del Curso está dedicada al coro I de la Antígona de Sófocles, luego de la «lectura» de algunos fragmentos de Parménides. De los versos 360 y 370 del coro, Heidegger elimina el punto y coma que, en las ediciones «canónicas», separa pantopóros de áporos y hypsípolis de ápolis. La unión de términos de opuesto significado ("no tener vías de salida» -áporos- quien es experto en todas ellas —pantopóros-, ni tener ciudad —ápolis - aquel que rige la ciudad — hypsípolis_-), pero que caracterizan aspectos fundamentales del ser-hombre: la vía y la casa, le permitía explicar el sentido del ser-hombre, definido en los versos iniciales del Coro: ser lo más inquietante (tò deinóteron) de entre las muchas cosas inquietantes (pollà tà deiná). Y el ser más inquieto, si recordamos la unheimliche Zweideutigkeit, el inquietante doble sentido de tò deinón ${ }^{45}$.

Ésa sería la mejor definición del propio Heidegger; ciertamente, preferible a la de su forzada «etimología».

Università S. Raffaele, Milán

witiello@libero.it

Vicenzo Vitiello

[Artículo aprobado para publicación en diciembre de 2016]

45 Cf. Heidegger, M. Einfürung in die Metaphysik, Niemeyer, Tübingen 1976 ${ }^{4}$, espec. pp. 112-126. 